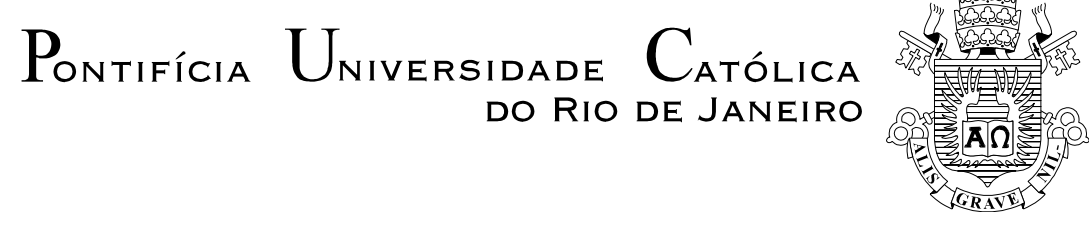

Paula Martins Salles

\title{
Associativismo e Militância: \\ o reconhecimento do funk como movimento cultural
}

Dissertação de Mestrado

Dissertação apresentada ao Programa de PósGraduação em Ciências Sociais da PUC-Rio como requisito parcial para obtenção do título de Mestre em Ciências Sociais.

Orientadora: Profa. Maria Alice Rezende de Carvalho 


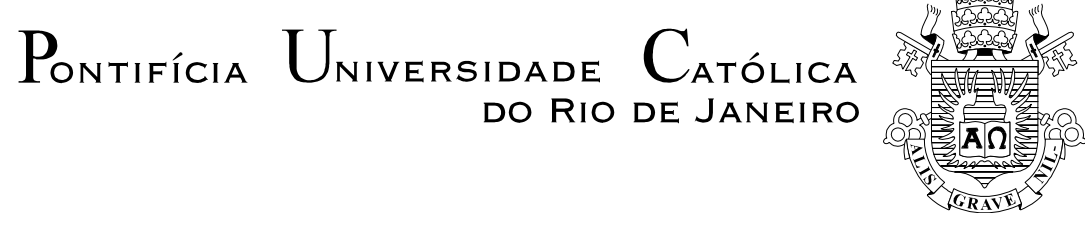

Paula Martins Salles

\begin{abstract}
Associativismo e Militância:
o reconhecimento do funk como movimento cultural
\end{abstract}

Dissertação apresentada como requisito parcial para obtenção do título de Mestre pelo Programa de Pós-Graduação em Ciências Sociais da PUCRio. Aprovada pela Comissão Examinadora abaixo assinada.

Profa. Maria Alice Rezende de Carvalho

Orientadora

Departamento de Sociologia e Política - PUC-Rio

Profa. Angela Maria de Randolpho Paiva Departamento de Sociologia e Política - PUC-Rio

Profa. Mariana Cavalcanti Rocha dos Santos

FGV/RJ

Profa. Mônica Herz Coordenadora Setorial do Centro de Ciências Sociais - PUC-Rio

Rio de Janeiro, 05 de agosto de 2011 
Todos os direitos reservados. É proibida a reprodução total ou parcial do trabalho sem autorização da universidade, do autor e do orientador.

Paula Martins Salles

Graduou-se em Ciências Sociais pela PUC-Rio em 2008. Atualmente, é pesquisadora do Centro de Estudos Direito e Sociedade, CEDES/PUC-Rio. Interessada nas áreas de sociologia urbana e sociologia do direito.

Ficha Catalográfica

Salles, Paula Martins

Associativismo e militância: o reconhecimento do funk como movimento cultural / Paula Martins Salles; orientadora: Maria Alice Rezende de Carvalho. 2011.

96 f. ; $30 \mathrm{~cm}$

Dissertação (mestrado)-Pontifícia Universidade Católica do Rio de Janeiro, Departamento de Sociologia e Política, 2011.

Inclui bibliografia

1. Sociologia - Teses. 2. Funk. 3. Reconhecimento. 4. Movimentos sociais. I. Carvalho, Maria Alice Rezende de. II. Pontifícia Universidade Católica do Rio de Janeiro. Departamento de Sociologia e Política. III. Título. 
Para Zi e Dante. 


\section{Agradecimentos}

Esse trabalho não poderia existir sem o auxílio e a contribuição de diversas pessoas com quem pude contar ao longo do percurso de realização do meu mestrado.

Meu agradecimento especial vai para minha orientadora, Maria Alice Rezende de Carvalho, não só pela clareza e direção que conferiu às minhas ideias em todos os nossos encontros acadêmicos e profissionais, mas principalmente pela amizade, carinho e compreensão que ela me dedicou ao longo da elaboração desse trabalho. Espero poder contar sempre com a sua amizade.

Agradeço ao Departamento de Sociologia e Política da PUC-Rio, em especial ao Prof. Marcelo Burgos, que, desde a minha entrada naquele departamento, há seis anos, acreditou em mim, abrindo a oportunidade para que eu trilhasse caminho profissional privilegiado. Ele me mostrou uma sociologia em comunicação com a vida, para além das fronteiras da academia. Agradeço a Profa. Angela Paiva, pela disciplina fundamental que ofereceu durante meu mestrado e que muito contribuiu para a elaboração desse trabalho. Agradeço também ao professor Paulo Jorge, pelo interesse demonstrado na minha dissertação a cada vez que nos encontrávamos. Conversar com ele era sempre uma forma de descortinar novos caminhos para o meu trabalho. Por fim, agradeço as secretárias do departamento, em especial a Ana Roxo, que cuida de todos nós com um carinho e uma dedicação que, acredito, nem sempre fazemos por merecer.

Agradeço profundamente ao Prof. Luiz Werneck Vianna, pela generosidade com que, desde o primeiro momento, me acolheu no Centro de Estudos Direito e Sociedade/CEDES, lugar em que me constituí profissionalmente, contando sempre com a sua confiança e seu apoio incondicional. Agradeço a todos os pesquisadores com que trabalhei no CEDES, em especial Fernando Perlatto, Ana Paula Carvalho, Carla Soares e Igor Suzano. Foi a relação entre ciência e 
vida pública, que descobri no CEDES, que me levou ao tema da minha dissertação.

Agradeço ao deputado Marcelo Freixo e a Guilherme Pimentel por terem feito a ponte necessária entre mim e a APAFunk, abrindo o campo da minha pesquisa. Agradeço especialmente ao MC Leonardo pela generosidade com que me abriu sua rotina à frente da associação e, principalmente, pela franqueza com que dividiu comigo sua trajetória no mundo do funk carioca.

À minha família, serei eternamente grata. À minha mãe, Tetê, pelo apoio incondicional em todas as horas. À minha avó, Myriam, que patrocinou o início dessa viagem. Ao meu primo, Zeca, meu grande amigo, que não poupou esforços para me ajudar. E a minha irmã, Nanã, por ser quem é.

Ao $\mathrm{Zi}$, meu amor, pela leitura minuciosa de tudo que escrevo, pela paciência com todas as minhas "crises", enfim, sem ele não teria chegado ao fim dessa jornada. Muito obrigada!

Finalmente, agradeço à CAPES, pelo auxílio financeiro para a realização dessa dissertação. 


\section{Resumo}

Salles, Paula Martins; Carvalho, Maria Alice Rezende de (Orientadora). Associativismo e Militância: o reconhecimento do funk como movimento cultural. Rio de Janeiro, 2011. 96p. Dissertação de Mestrado Departamento de Sociologia e Política, Pontifícia Universidade Católica do Rio de Janeiro.

Nos últimos vinte anos, o funk tem sido uma das principais expressões culturais dos jovens das camadas populares do Rio de Janeiro. Porém, sua trajetória é bastante conturbada, ao mesmo tempo em que ganhava espaço na cena cultural da cidade, o funk também foi alvo de um processo de intensa perseguição e discriminação. Esse trabalho vai focalizar na Associação dos Profissionais e Amigos do Funk/APAFunk, criada por jovens funkeiros com o objetivo de lutar pelo reconhecimento do funk como movimento cultural e pela profissionalização de seus operadores, com o intuito de combater a exploração excessiva vigente no mercado do funk na atualidade. A hipótese central desse trabalho é a de que a organização em uma associação confere a eles um novo espaço de vocalização e liderança, em que a luta pelo funk, além de ser uma luta pela validação e respeito aos códigos culturais produzidos por esses jovens, é também uma luta pela ressignificação da posição social desses jovens e pela ampliação da democracia.

\section{Palavras-chave}

Funk; reconhecimento; movimentos sociais. 


\section{Abstract}

Salles, Paula Martins; Carvalho, Maria Alice Rezende de (Advisor) Associativism and Militancy: recognition of funk as a cultural movement. Rio de Janeiro, 2011. 96p. MSc. Dissertation - Departamento de Sociologia e Política, Pontifícia Universidade Católica do Rio de Janeiro.

Over the past twenty years, funk has been one of the major cultural expressions of young people from the popular classes in Rio de Janeiro. However, its trajectory is very troubled, while funk earned space in the city's cultural scene, it was also subject to a process of intense persecution and discrimination. This work will focus on the Associação dos Profissionais e Amigos do Funk /APAFunk, created by young funkeiros in order to fight for recognition of funk as a cultural movement and the professionalization of its operators, in order to combat the exploitation of the prevailing funk market today. The central hypothesis of this work is that organizing in an association gives them a new space of vocalization and leadership. The struggle for funk as well as being a struggle for validation and respect for cultural codes produced by these young people is also a struggle for the redefinition of the social position of these young people and the expansion of democracy.

\section{Keywords}

Funk; recognition; social movements 


\section{Sumário}

$\begin{array}{ll}\text { 1. Introdução } & 10\end{array}$

2. Metrô Cinelândia: funk e acesso à cidade

3. Chapa Quente: revolta e mercado

4. Favela Traduzida: funkeiros e mediadores culturais

5. Considerações Finais

6. Referências Bibliográficas

89

Anexo

93 